\title{
Análise do comportamento das temperaturas médias e máximas diárias no município de Uberaba - MG, por meio de curvas de permanência no período de 1970 - 2015
}

\author{
Lucas Rafael Tiago Silva ${ }^{(a)}$,Luiz Antônio de Oliveira ${ }^{(b)}$ \\ (a) Instituto de Geografia, Universidade Federal de Uberlândia, lucasrafaelts@geo.ufu.br \\ (b) Instituto de Geografia, Universidade Federal de Uberlândia, luizantonio@ig.ufu.br
}

Eixo: Climatologia em Diferentes Níveis Escalares: Mudanças e Variabilidades

Resumo:

\begin{abstract}
O trabalho tem como objetivo identificar e analisar os resultados da curva de permanência, essa que segundo Tucci (2004), relaciona o nível de ocorrência de algum evento e a probabilidade de ocorrer tal evento em igual ou maior intensidade. Foram utilizados dados de temperatura média e máxima da estação convencional do município de Uberaba - MG, compreendendo uma série histórica de 46 anos(1970 a 2015). Os resultados encontrados mostram que os dados seguem uma tendência nos valores de temperatura, onde os dados com o maior valor, ou seja, as anomalias, representam $5 \%$ dos dados, enquanto que os demais dados representam os outros 95\%. Trabalhos que desenvolvem temáticas de padronizações se tornam cada vez mais úteis para a sociedade, visto que estes podem prever possíveis tendências e anomalias.
\end{abstract}

Palavras chave: Temperatura; Curva de Permanência; Tendência; Anomalia; Uberaba.

\section{Introdução}

Segundo Ayoade (1996), temperatura é um dos elementos mais analisados do sistema atmosférico, podendo variar de um lugar para outro como no decorrer do tempo em determinadas regiões. Esta variação pode ser explicada por diversos fatores, como relevo, altitude, ventos, correntes oceânicas, volume de insolação, dentre outros. Assim, o aumento da temperatura média local ou mundial, pode gerar diversos impactos ao planeta e também às pessoas, sejam esses impactos de natureza ambiental, social, econômica ou política.

Os estudos a respeito da temática se intensificaram na década de 1980, afim de tentarem minimizar os efeitos das mudanças climáticas.

“(...)em 1988, foi estabelecido o Painel Intergovernamental de Mudanças Climáticas, IPCC (IntergovernmetalPanelonClimateChange). O IPCC é uma vasta rede de cientistas dedicados à avaliação do conhecimento científico sobre mudança climática e suas ligações com a sociedade humana." (CAMPOS; BRAGA; ALVES, 2006)

Segundo Santos (2006), os fatores que podem influenciar o clima em escala regional são a degradação ambiental e o desmatamento, estes que contribuem para alterações no sistema global, porém, para análise em escala local, a temperatura do ar e a precipitação pluvial, possuem uma maior efetividade na detecção de alterações climáticas. 


\section{OS DESAFIOS DA GEOGRAFIA FÍSICA NA FRONTEIRA DO CONHECIMENTO \\ Instituto de Geociências - Unicamp \\ Campinas - SP \\ 28 de Junho à 02 de Julho de 2017}

Trabalhos que desenvolvem temáticas com padronizações de dados, se tornam cada vez mais importantes, visto que estes podem prever possíveis tendências e anomalias. "Estes estudos podem ser usados como ferramentas de planeamento, mitigando assim problemas futuros promovidos por alterações climáticas". (OLIVEIRA; SILVA, 2015, p.1113)

Segundo Tucci (2004), a curva de permanência relaciona o nível de ocorrência de algum evento e a probabilidade de ocorrer tal evento em igual ou maior intensidade. Ela é determinada com base em valores diários, semanais ou mensais. A curva de permanência é comumente usada para estudos de vazões, mas como se trata de análises estatísticas, pode ser aplicada também a outros estudos, como os de precipitação e temperatura.

O município de Uberaba, situa-se na mesorregião do Triângulo Mineiro e Alto Paranaíba, no estado de Minas Gerais. Sua extensão territorial é de $4.523,957 \mathrm{~km}^{2}$ e sua população estimada para o ano de 2015, é de 322.126 habitantes (IBGE, 2010). A estação meteorológica convencional de Uberaba, de código (OMM: 83577), encontra-se na área urbana, sob as coordenadas geográficas -19.73 de latitude e - 47.95 de longitude, com altitude de 737 metros em relação ao nível do mar.

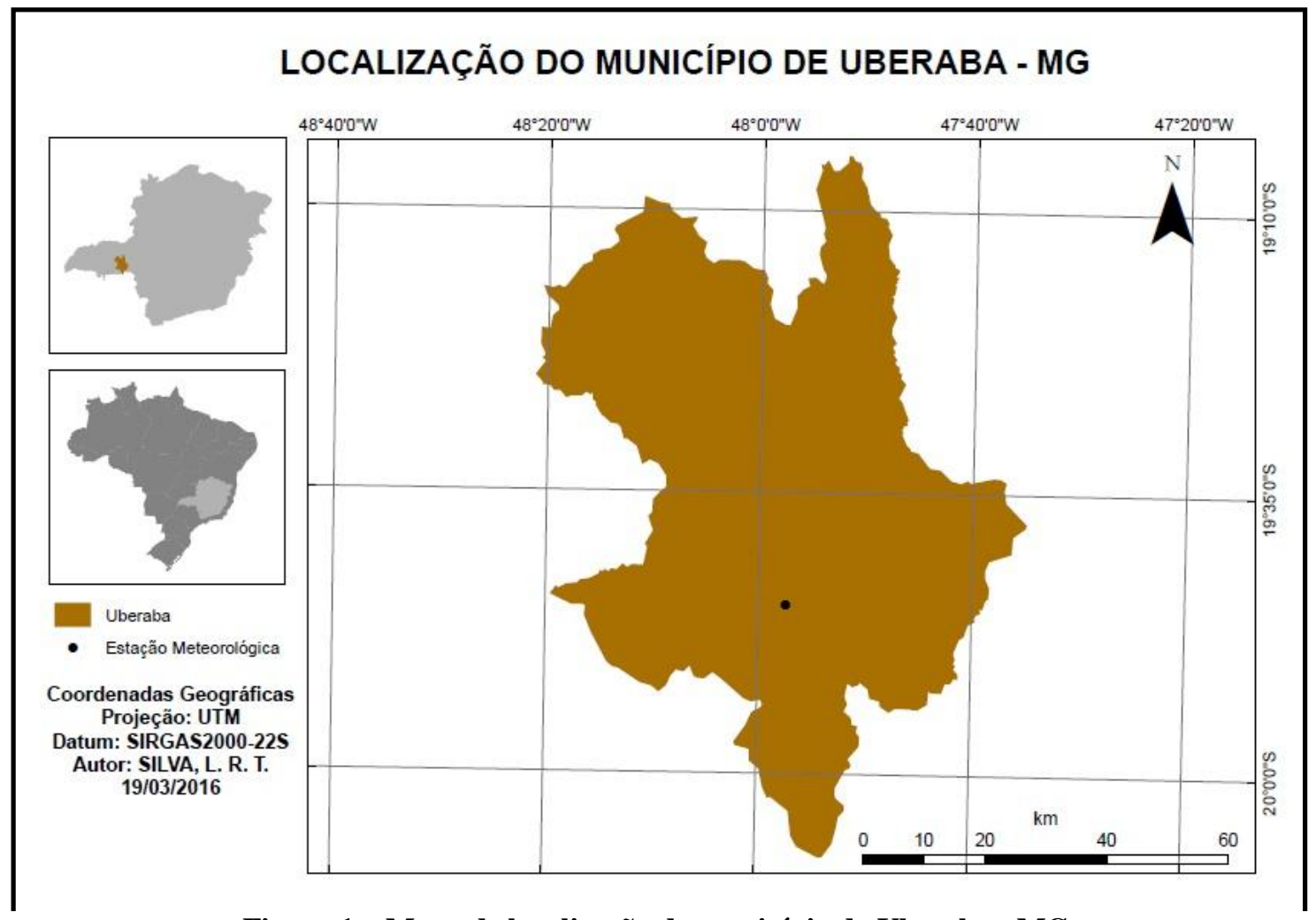

Figura 1 - Mapa de localização do município de Uberaba - MG

Fonte dos dados: IBGE (2010) - Acessado em novembro de 2016

Organização: SILVA (2016) 


\section{OS DESAFIOS DA GEOGRAFIA FÍSICA NA FRONTEIRA DO CONHECIMENTO \\ Instituto de Geociências - Unicamp \\ Campinas - SP \\ 28 de Junho à 02 de Julho de 2017}

\section{Materiais e Métodos}

Para a realização deste trabalho, primeiramente foi elaborado um referencial teórico sobre o tema proposto. Para a realização dos cálculos foram utilizados dados de temperatura média e máxima da estação convencional da cidade de Uberaba - MG, código OMM: 83577, compreendendo uma série histórica de 46 anos (1970 - 2015). Os dados foram disponibilizados pelo Banco de Dados Meteorológicos para Ensino e Pesquisa (BDMEP), do Instituto Nacional de Meteorologia (INMET).

O tratamento estatístico dos dados foi realizado em planilha eletrônica do Microsoft Excel. Para a construção da curva de permanência estes dados foram organizados em forma de matriz, onde, encontrou-se o número de elementos da amostra (n), para determinar a amplitude de variação das temperaturas, seguiu-se a equação I:

$$
A=\text { Tmáx - Tmín Equação I }
$$

Onde:

A: Amplitude dos dados;

Tmáx: Maior valor de temperatura;

Tmín: Menor valor de temperatura;

Com a amplitude definida, estabeleceu-se o número de intervalo de classes $(\mathrm{N})$, conforme índica a equação II.

$$
N=1+3,3 * \log n \quad \text { Equação II }
$$

Onde:

$\mathrm{N}$ : Número de intervalos de classes

n: Número de elementos da amostra.

Para realizar a distribuição dos dados, de acordo com a amplitude total do intervalo de classes (K), utilizou-se a equação III.

$$
K=\frac{A}{N} \quad \text { Equação III }
$$

Onde:

K: Amplitude dos intervalos de classes;

A: Amplitude dos dados;

$\mathrm{N}$ : Número de intervalo de classes; 
Após a elaboração destes parâmetros, foi possível calcular a frequência absoluta, absoluta acumulada, relativa e relativa acumulada e, assim, foi possível gerar os gráficos de curva de permanência para a série histórica.

Para elaboração do mapa de localização foram utilizados dados fornecidos pelo Instituto Brasileiro de Geografia e Estatística (IBGE), os mesmos foram manipulados no software de informação geográfica ArcGis 10.1 .

\section{Resultados}

Partindo do princípio de que foi gerado um gráfico de curva de permanência para toda a série histórica - um gráfico para as temperaturas médias e um gráfico para as temperaturas máximas - podendo destacar assim, as temperaturas extremas da série histórica. Foram gerados também gráficos para análise da curva de permanência, dividindo a série histórica em décadas, objetivando-se assim, analisar a possibilidade de alguma anomalia significativa de temperatura entre as décadas.

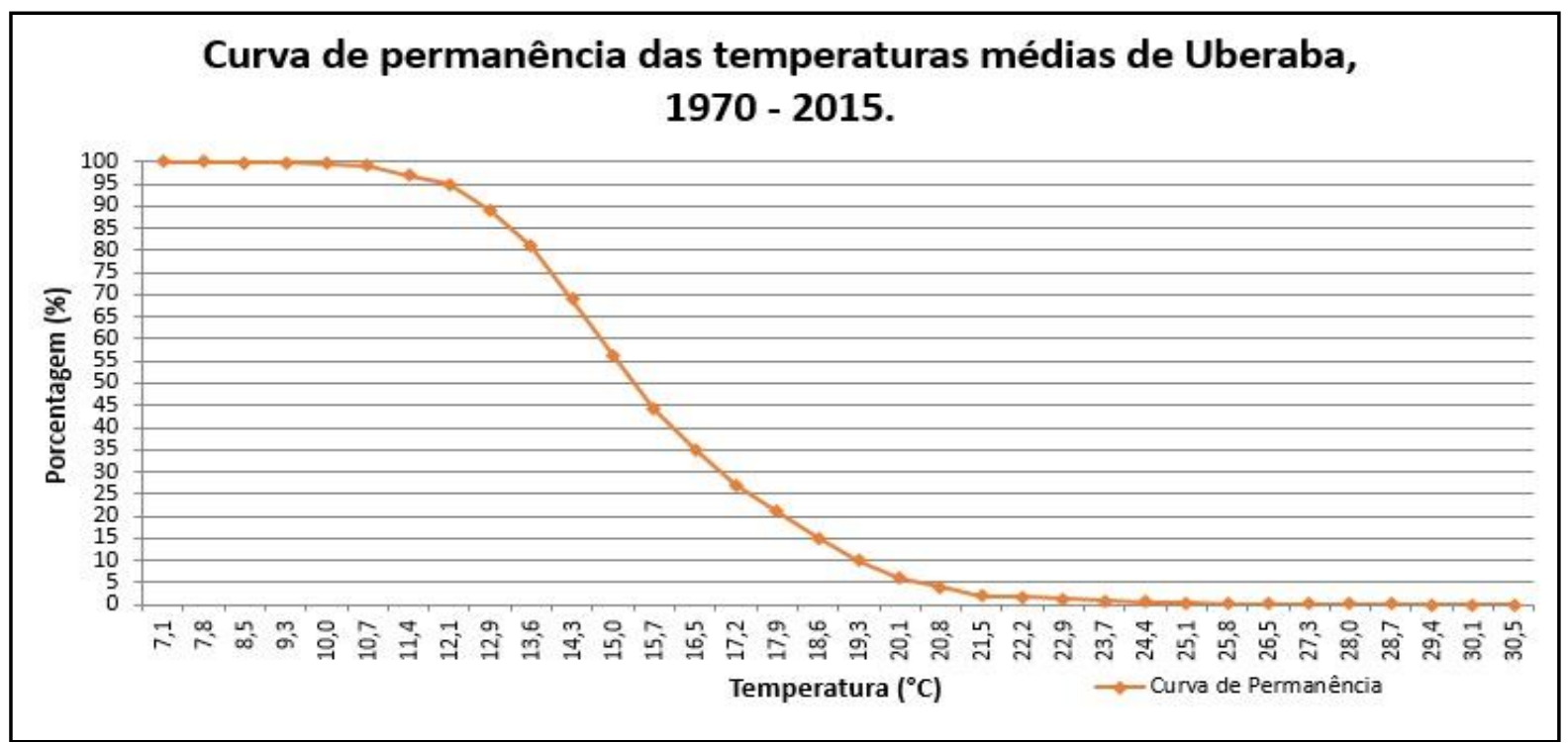

Figura 02 - Curva de permanência das temperaturas médias de Uberaba, 1970 - 2015 Fonte dos dados: INMET (2016) - Acessado em março de 2016 Organização: SILVA (2016)

Os dados de temperatura média que foram utilizados para a confecção do histograma de curva de permanência (figura 02), representam um total de 14.102 dias de dados analisados, no período de 1970 a 2015 , onde estes variaram de $7,1^{\circ} \mathrm{C}$ a $30,5^{\circ} \mathrm{C}$, estabelecendo-se assim uma amplitude termal de $23,4^{\circ} \mathrm{C}$. Observou-se que do total de dias analisados, 678 dias compreenderam $5 \%$ dos dados, com temperaturas que variavam de $26,5^{\circ} \mathrm{C}$ a $30,5^{\circ} \mathrm{C}$, enquanto que os demais 13.424 dias, representaram $95 \%$ dos valores, obtendo temperaturas que variavam de $7,1^{\circ} \mathrm{C}$ a $25,8^{\circ} \mathrm{C}$. 

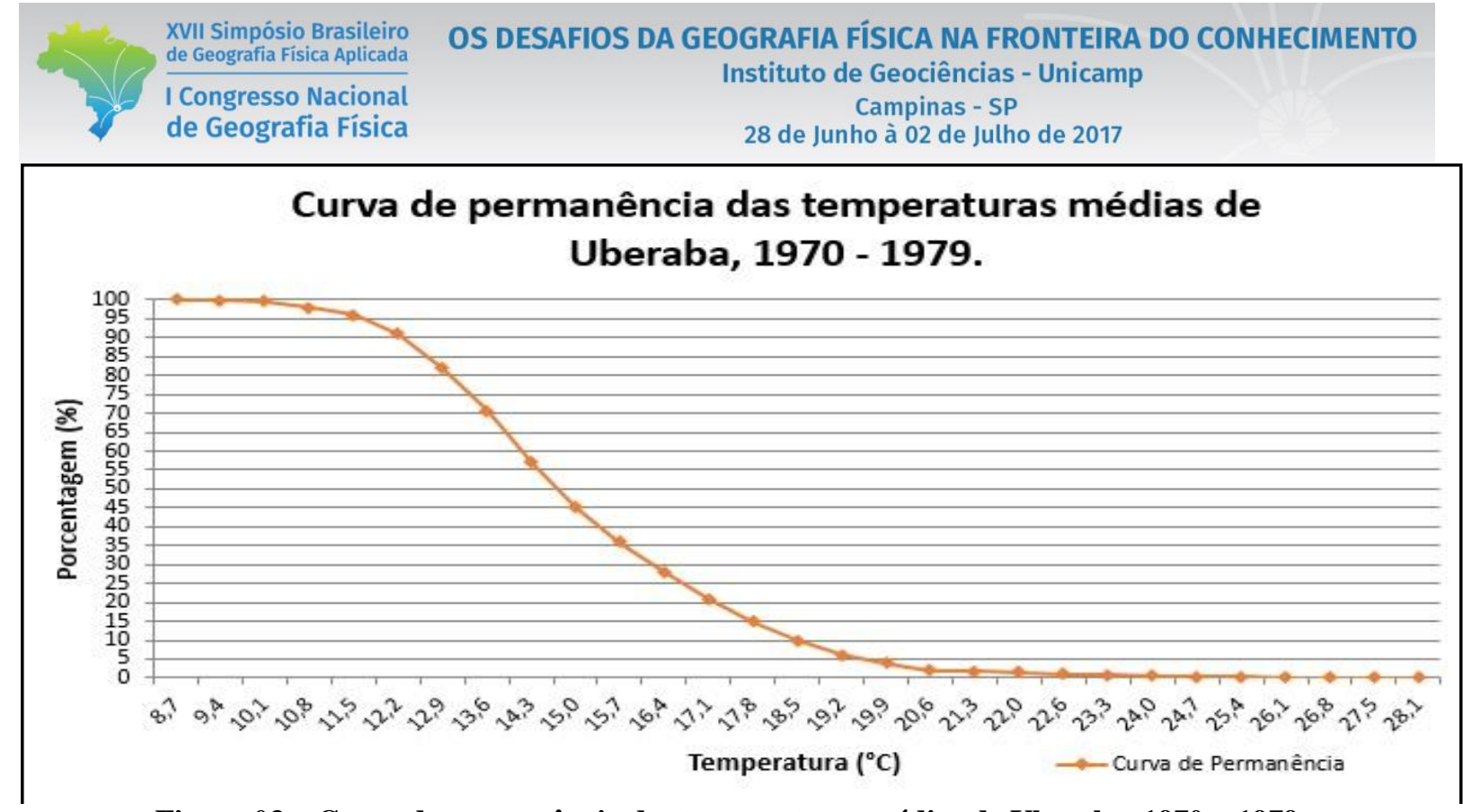

Figura 03 - Curva de permanência das temperaturas médias de Uberaba, 1970 - 1979

Fonte dos dados: INMET (2016) - Acessado em março de 2016

Organização: SILVA (2016)

Avaliando o histograma que representa a década de 1970 (Figura 03), foram analisados 3.294 dias, onde a temperatura média variou de $8,7^{\circ} \mathrm{C}$ a $28,1^{\circ} \mathrm{C}$, resultando em uma amplitude termal de $19^{\circ} \mathrm{C}$. Observou-se que do total de dias analisados, 164 dias compreenderam 5\% dos dados, com temperaturas que variavam de $25,4^{\circ} \mathrm{C}$ a $28,1^{\circ} \mathrm{C}$, enquanto que os demais 3.130 dias, representaram $95 \%$ dos valores, obtendo temperaturas que variavam de $8,7^{\circ} \mathrm{C}$ a $25,3^{\circ} \mathrm{C}$.

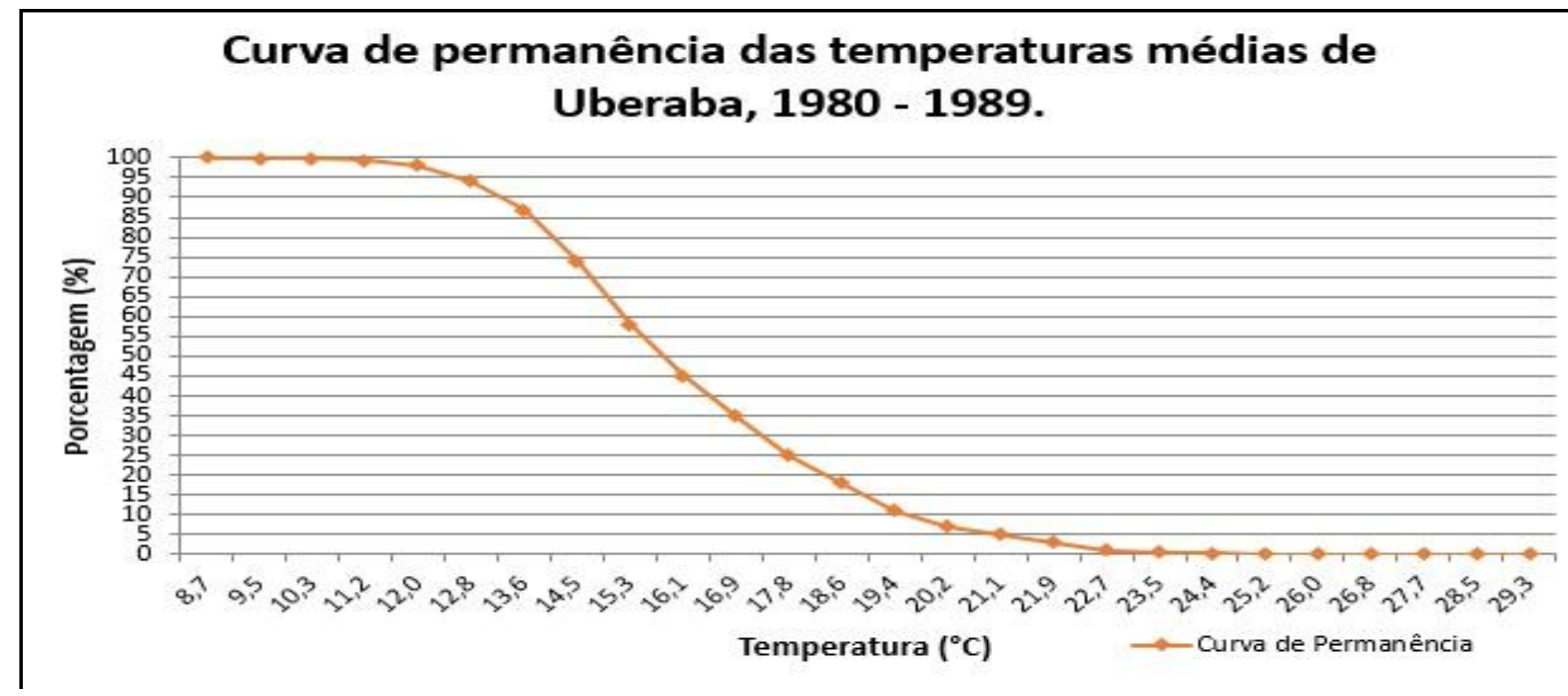

Figura 04 - Curva de permanência das temperaturas médias de Uberaba, 1980 - 1989 Fonte dos dados: INMET (2016) - Acessado em março de 2016

Organização: SILVA (2016)

Os dados de temperatura média que foram utilizados para a confecção do histograma de curva de permanência (figura 04), representam um total de 1.416 dias de dados analisados, no período de 1980 a 1989 , onde estes variaram de $8,7^{\circ} \mathrm{C}$ a $29,3^{\circ} \mathrm{C}$, estabelecendo-se assim uma amplitude termal de $20,6^{\circ} \mathrm{C}$. Observou-se que do total de dias analisados, 08 dias compreenderam $5 \%$ dos dados, com 

OS DESAFIOS DA GEOGRAFIA FÍSICA NA FRONTEIRA DO CONHECIMENTO Instituto de Geociências - Unicamp
Campinas - SP
28 de Junho à 02 de Julho de 2017

temperaturas que variavam de $27,7^{\circ} \mathrm{C}$ a $29,3^{\circ} \mathrm{C}$, enquanto que os demais 1.408 dias, representaram $95 \%$ dos valores, obtendo temperaturas que variavam de $8,7^{\circ} \mathrm{C}$ a $27,6^{\circ} \mathrm{C}$.

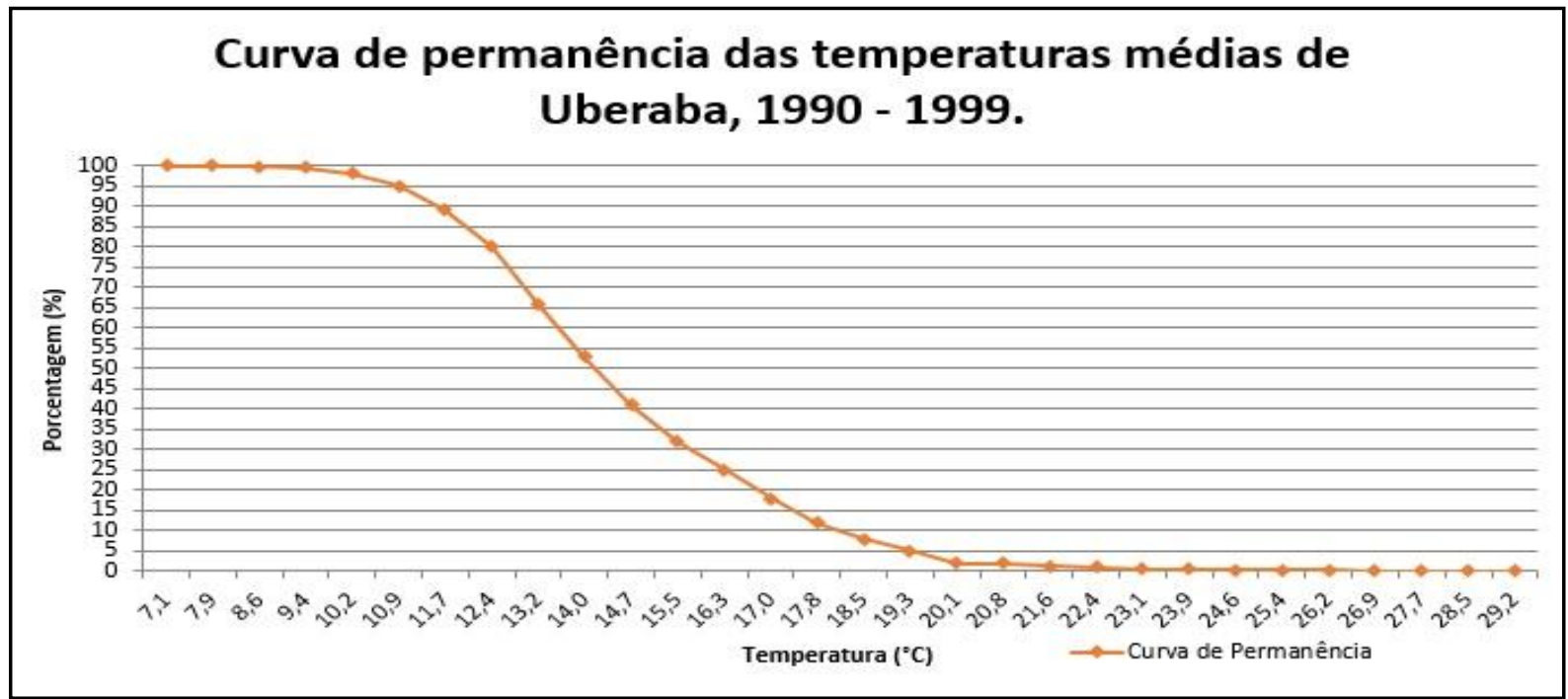

Figura 05 - Curva de permanência das temperaturas médias de Uberaba, 1990 - 1999 Fonte dos dados: INMET (2016) - Acessado em março de 2016

Organização: SILVA (2016)

Os dados de temperatura média que foram utilizados para a confecção do histograma de curva de permanência (figura 05), representam um total de 3.637 dias de dados analisados, no período de 1990 a 1999 , onde estes variaram de $7,1^{\circ} \mathrm{C}$ a $28,5^{\circ} \mathrm{C}$, estabelecendo-se assim uma amplitude termal de $21,4^{\circ} \mathrm{C}$. Observou-se que do total de dias analisados, 172 dias compreenderam 5\% dos dados, com temperaturas que variavam de $26,2^{\circ} \mathrm{C}$ a $29,2^{\circ} \mathrm{C}$, enquanto que os demais 3.465 dias, representaram $95 \%$ dos valores, obtendo temperaturas que variavam de $7,1^{\circ} \mathrm{C}$ a $26,1^{\circ} \mathrm{C}$.

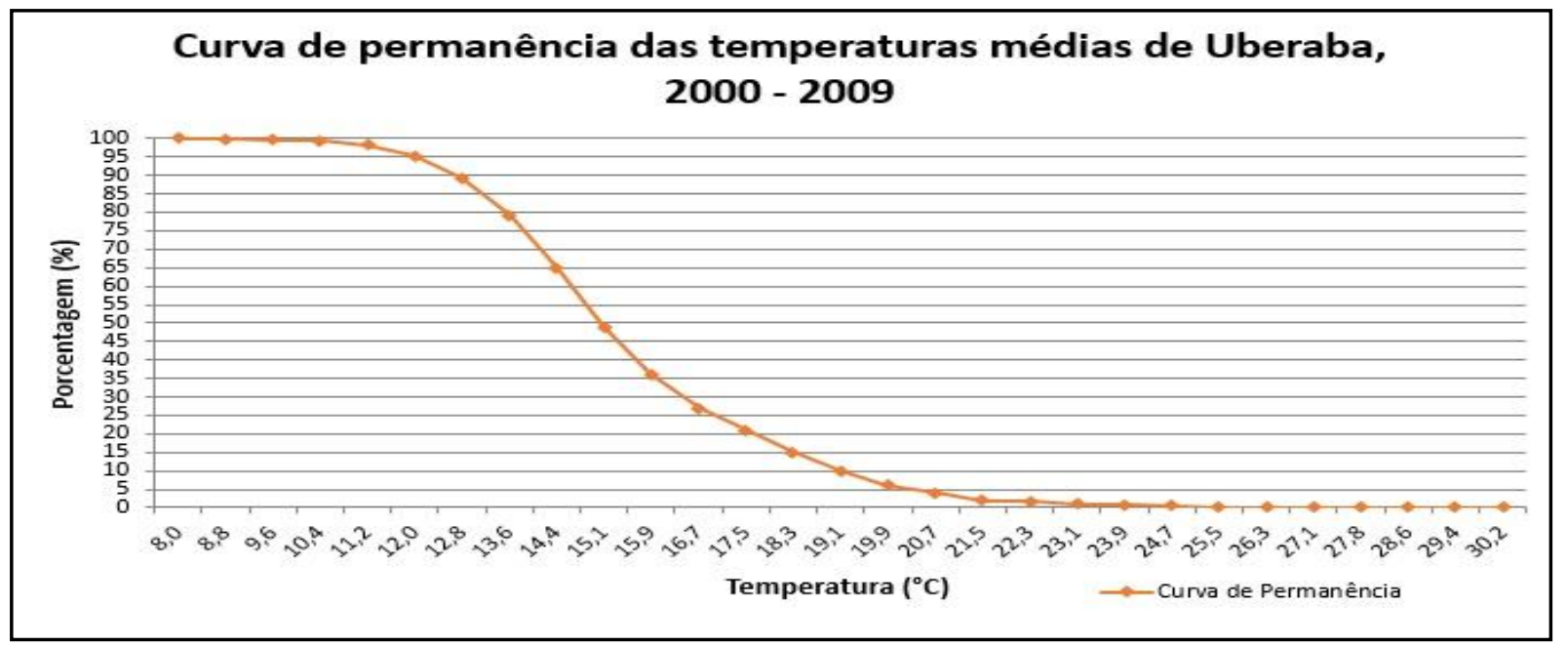

Figura 06 - Curva de permanência das temperaturas médias de Uberaba, 2000 - 2009 Fonte dos dados: INMET (2016) - Acessado em março de 2016 Organização: SILVA (2016) 
Os dados de temperatura média que foram utilizados para a confecção do histograma de curva de permanência (figura 06), representam um total de 3.564 dias de dados analisados, no período de 2000 a 2009 , onde estes variaram de $8,0^{\circ} \mathrm{C}$ a $30,2^{\circ} \mathrm{C}$, estabelecendo-se assim uma amplitude termal de $22,2^{\circ} \mathrm{C}$. Observou-se que do total de dias analisados, 170 dias compreenderam $5 \%$ dos dados, com temperaturas que variavam de $27,1^{\circ} \mathrm{C}$ a $30,2^{\circ} \mathrm{C}$, enquanto que os demais 3.394 dias, representaram $95 \%$ dos valores, obtendo temperaturas que variavam de $8,0^{\circ} \mathrm{C}$ a $27,0^{\circ} \mathrm{C}$.

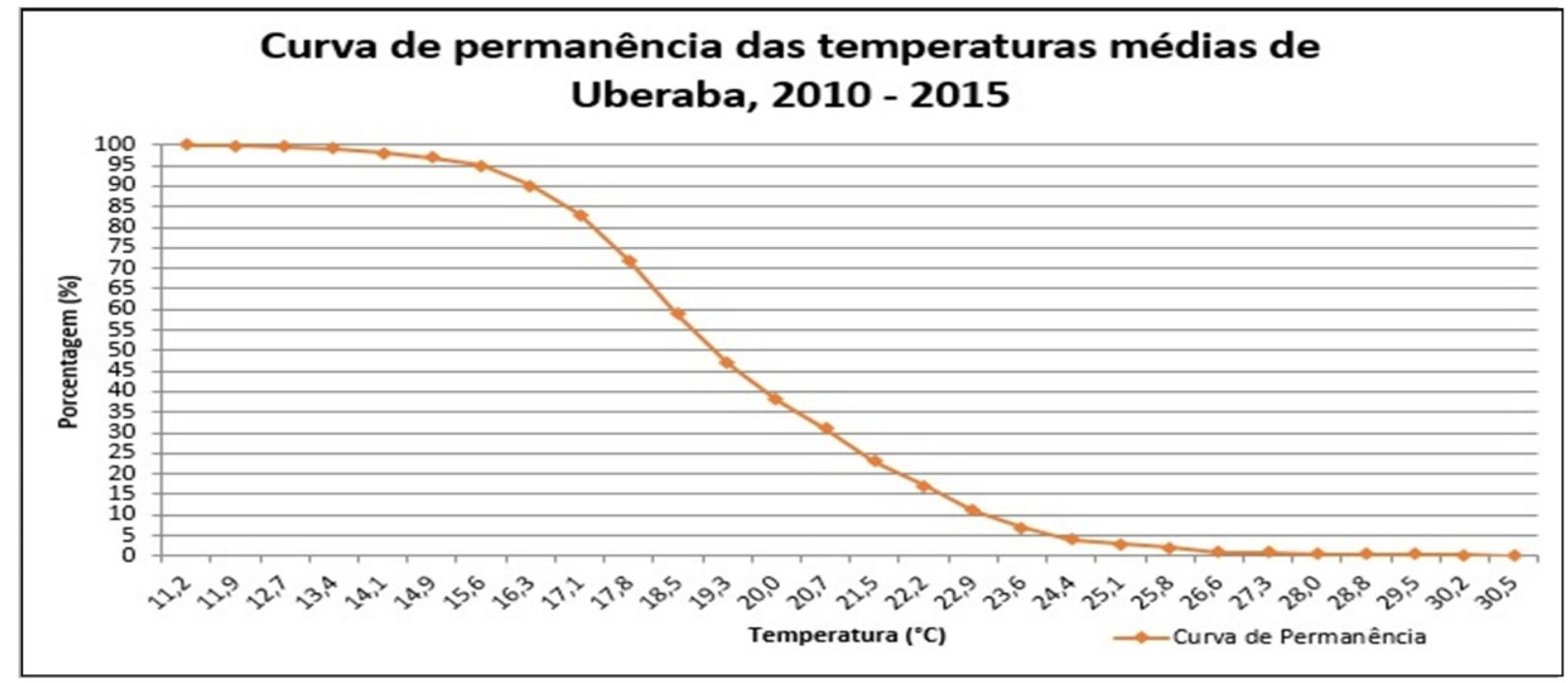

Figura 07 - Curva de permanência das temperaturas médias de Uberaba, 2010 - 2015 Fonte dos dados: INMET (2016) - Acessado em março de 2016

Organização: SILVA (2016)

Os dados de temperatura média que foram utilizados para a confecção do histograma de curva de permanência (figura 07), representam um total de 2.191 dias de dados analisados, no período de 2010 a 2015 , onde estes variaram de $11,2^{\circ} \mathrm{C}$ a $30,5^{\circ} \mathrm{C}$, estabelecendo-se assim uma amplitude termal de $19,3^{\circ} \mathrm{C}$. Observou-se que do total de dias analisados, 16 dias compreenderam $5 \%$ dos dados, com temperaturas que variavam de $29,5^{\circ} \mathrm{C}$ a $30,5^{\circ} \mathrm{C}$, enquanto que os demais 2.175 dias, representaram $95 \%$ dos valores, obtendo temperaturas que variavam de $11,2^{\circ} \mathrm{C}$ a $29,4^{\circ} \mathrm{C}$. 


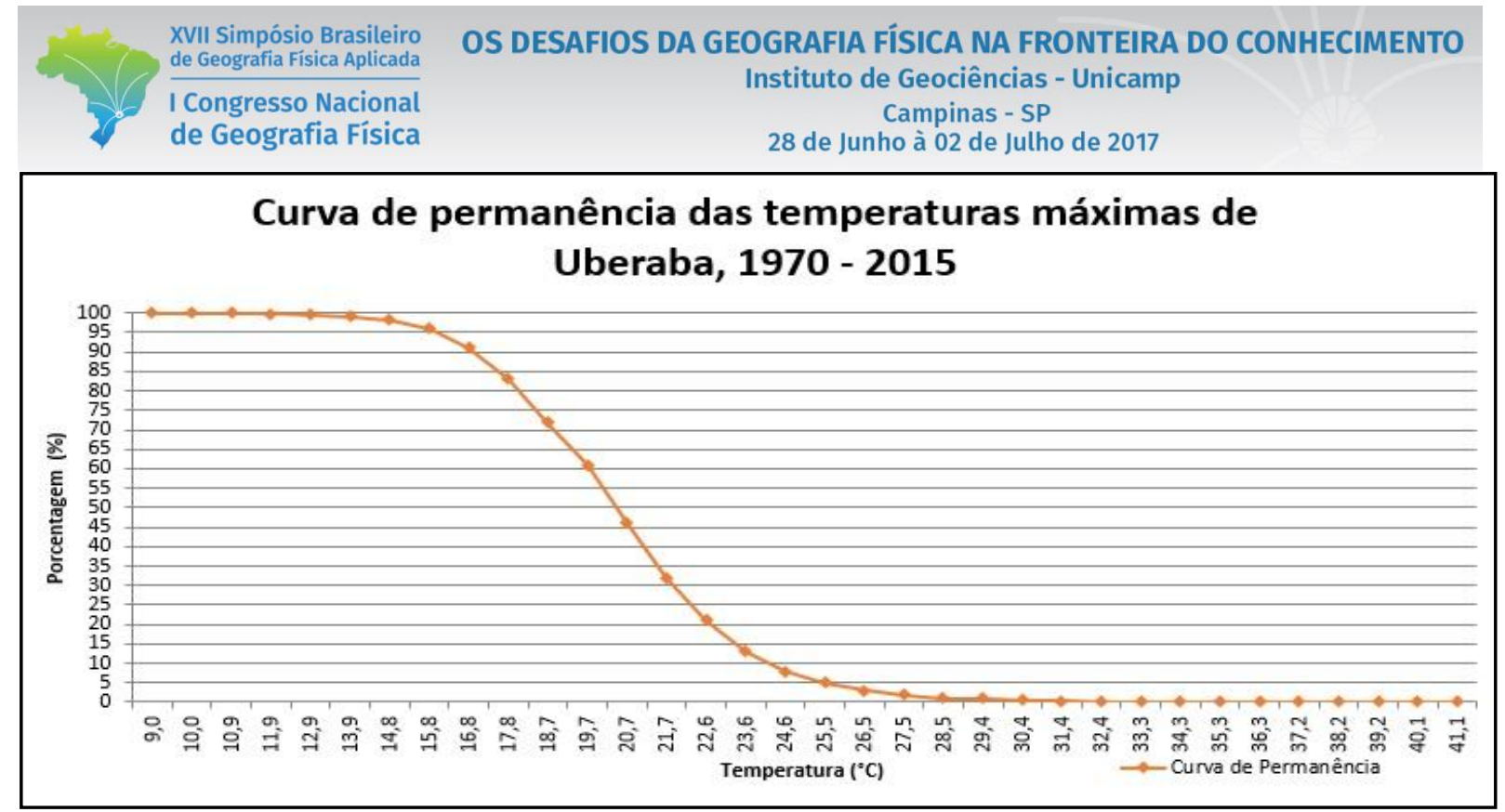

Figura 08 - Curva de permanência das temperaturas máximas de Uberaba, 1970 - 2015 Fonte dos dados: INMET (2016) - Acessado em março de 2016

Organização: SILVA (2016)

Os dados de temperatura máxima que foram utilizados para a confecção do histograma de curva de permanência (figura 08), representam um total de 14.265 dias de dados analisados, no período de 1970 a 2015 , onde estes variaram de $9,0^{\circ} \mathrm{C}$ a $40,7^{\circ} \mathrm{C}$, estabelecendo-se assim uma amplitude termal de $31,7^{\circ} \mathrm{C}$. Observou-se que do total de dias analisados, 77 dias compreenderam 5\% dos dados, com temperaturas que variavam de $37,2^{\circ} \mathrm{C}$ a $40,7^{\circ} \mathrm{C}$, enquanto que os demais 14.188 dias, representaram $95 \%$ dos valores, obtendo temperaturas que variavam de $9,0^{\circ} \mathrm{C}$ a $37,1^{\circ} \mathrm{C}$.

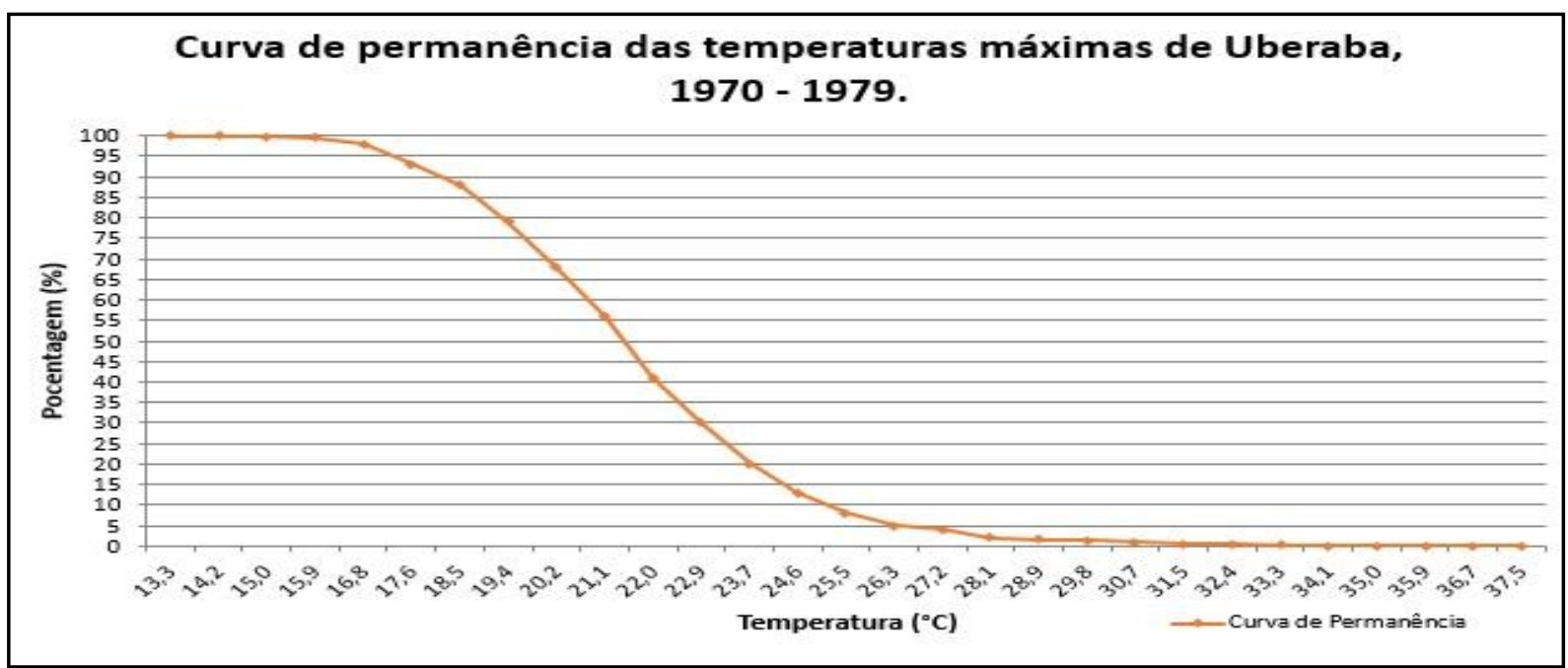

Figura 09 - Curva de permanência das temperaturas máximas de Uberaba, 1970 - 1979 Fonte dos dados: INMET (2016) - Acessado em março de 2016 Organização: SILVA (2016)

Os dados de temperatura máxima que foram utilizados para a confecção do histograma de curva de permanência (figura 09), representam um total de 3.432 dias de dados analisados, no período de 1970 a 1979 , onde estes variaram de $13,3^{\circ} \mathrm{C}$ a $37,5^{\circ} \mathrm{C}$, estabelecendo-se assim uma amplitude termal de 
$24,2^{\circ} \mathrm{C}$. Observou-se que do total de dias analisados, 215 dias compreenderam $5 \%$ dos dados, com temperaturas que variavam de $34,1^{\circ} \mathrm{C}$ a $37,5^{\circ} \mathrm{C}$, enquanto que os demais 3.217 dias, representaram $95 \%$ dos valores, obtendo temperaturas que variavam de $13,3^{\circ} \mathrm{C}$ a $34,0^{\circ} \mathrm{C}$.

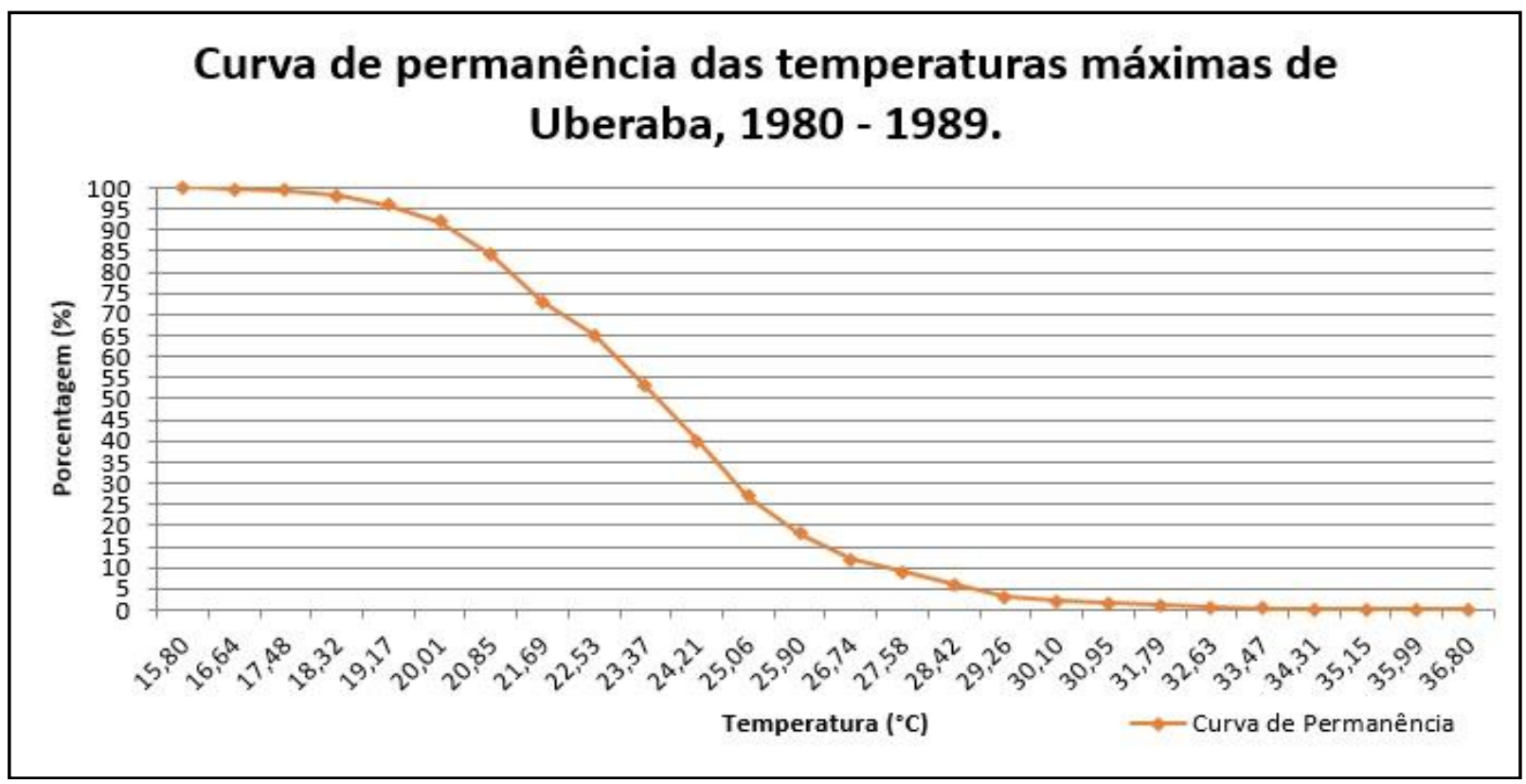

Figura 10 - Curva de permanência das temperaturas máximas de Uberaba, 1980 - 1989 Fonte dos dados: INMET (2016) - Acessado em março de 2016 Organização: SILVA (2016)

Os dados de temperatura máxima que foram utilizados para a confecção do histograma de curva de permanência (figura 10), representam um total de 1.422 dias de dados analisados, no período de 1980 a 1989 , onde estes variaram de $15,8^{\circ} \mathrm{C}$ a $36,8^{\circ} \mathrm{C}$, estabelecendo-se assim uma amplitude termal de $21,0^{\circ} \mathrm{C}$. Observou-se que do total de dias analisados, 09 dias compreenderam 5\% dos dados, com temperaturas que variavam de $35,9^{\circ} \mathrm{C}$ a $36,8^{\circ} \mathrm{C}$, enquanto que os demais 1.413 dias, representaram $95 \%$ dos valores, obtendo temperaturas que variavam de $15,8^{\circ} \mathrm{C}$ a $35,8^{\circ} \mathrm{C}$. 


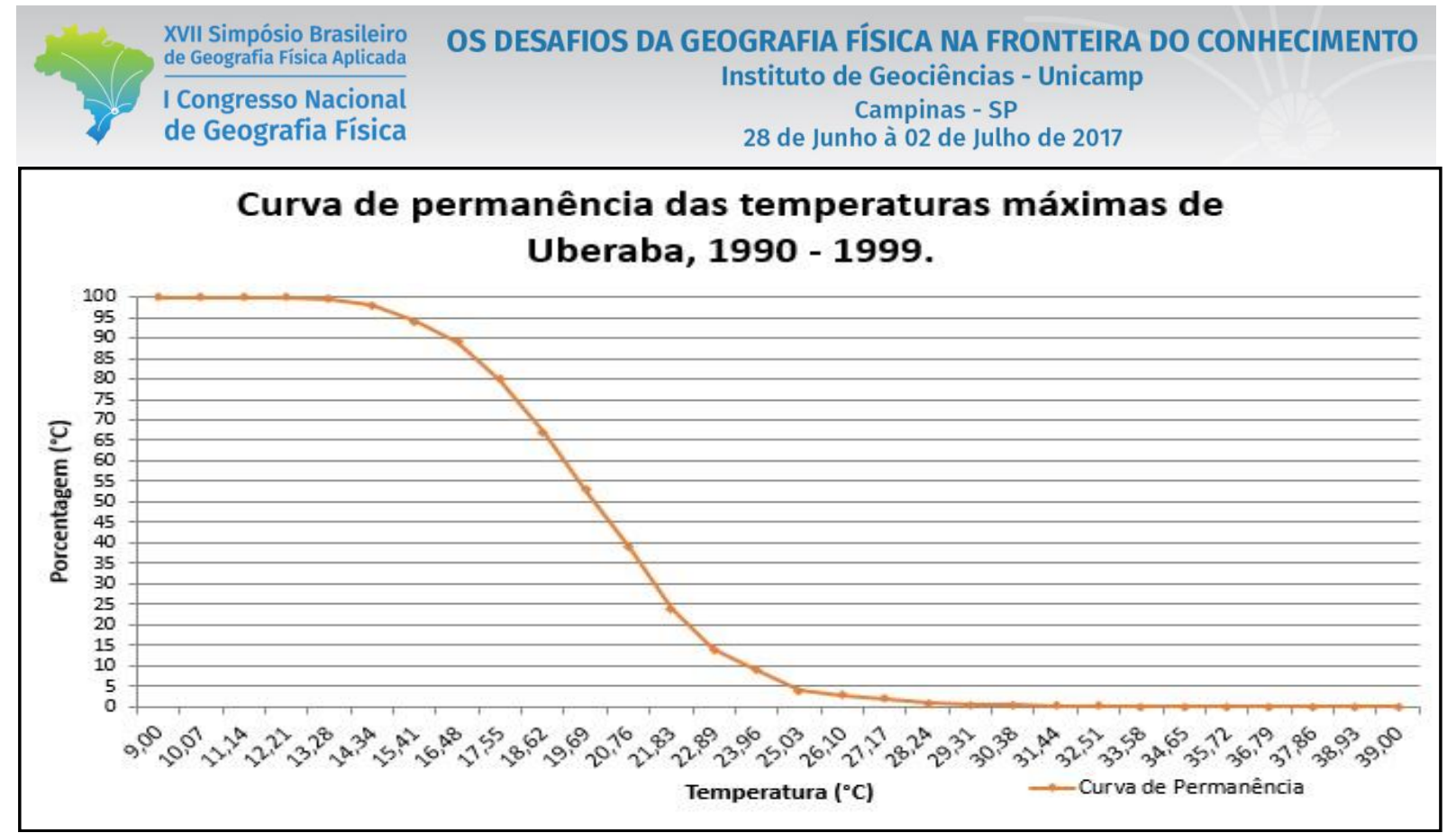

Figura 11 - Curva de permanência das temperaturas máximas de Uberaba, 1990 - 1999 Fonte dos dados: INMET (2016) - Acessado em março de 2016

Organização: SILVA (2016)

Os dados de temperatura máxima que foram utilizados para a confecção do histograma de curva de permanência (figura 11), representam um total de 3.652 dias de dados analisados, no período de 1990 a 1999 , onde estes variaram de $9,0^{\circ} \mathrm{C}$ a $39,0^{\circ} \mathrm{C}$, estabelecendo-se assim uma amplitude termal de $30,0^{\circ} \mathrm{C}$. Observou-se que do total de dias analisados, 02 dias compreenderam $5 \%$ dos dados, com temperaturas que variavam de $37,8^{\circ} \mathrm{C}$ a $39,0^{\circ} \mathrm{C}$, enquanto que os demais 3.650 dias, representaram $95 \%$ dos valores, obtendo temperaturas que variavam de $9,0^{\circ} \mathrm{C}$ a $37,6^{\circ} \mathrm{C}$.

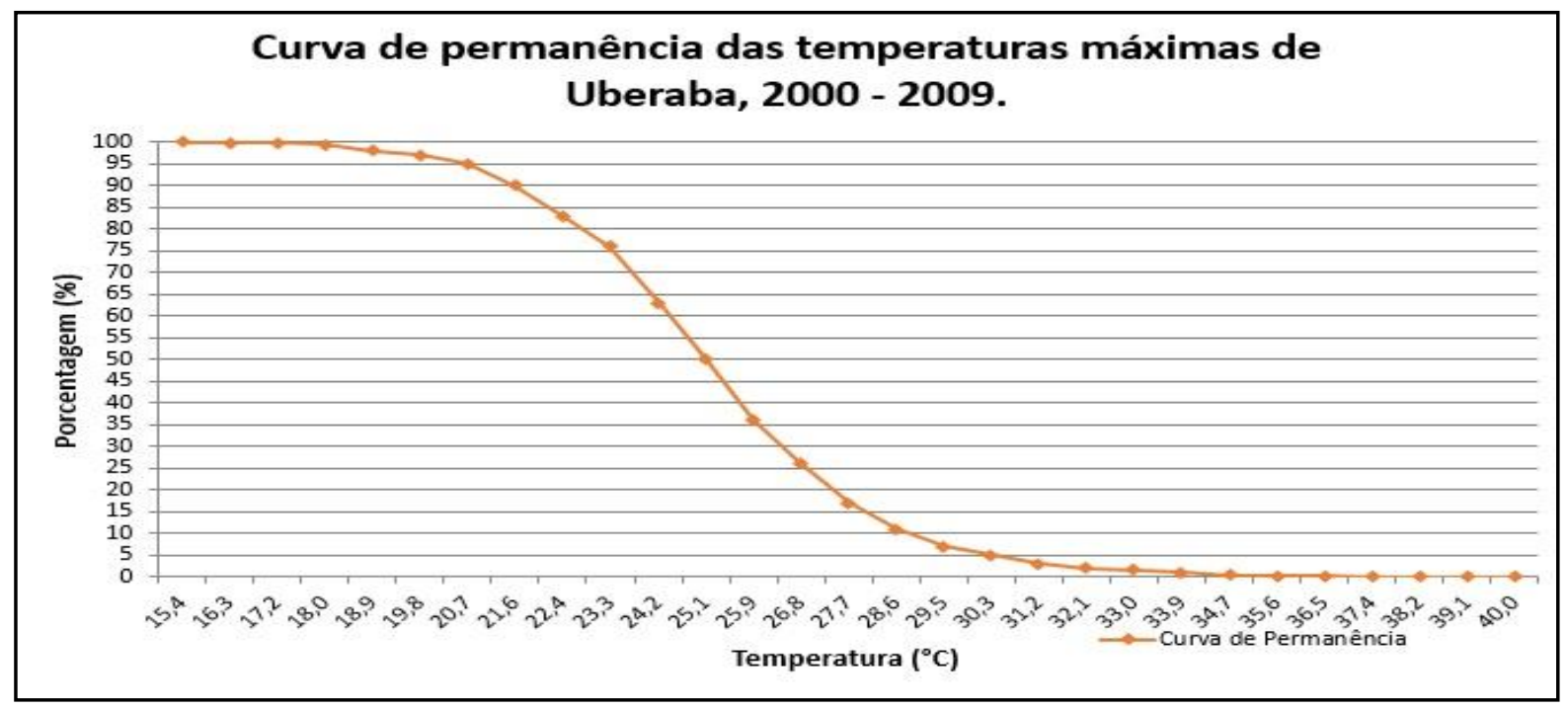

Figura 12 - Curva de permanência das temperaturas máximas de Uberaba, 2000 - 2009 Fonte dos dados: INMET (2016) - Acessado em março de 2016 Organização: SILVA (2016)

Os dados de temperatura máxima que foram utilizados para a confecção do histograma de curva de permanência (figura 12), representam um total de 3.568 dias de dados analisados, no período de 2000 


\author{
OS DESAFIOS DA GEOGRAFIA FÍSICA NA FRONTEIRA DO CONHECIMENTO \\ Instituto de Geociências - Unicamp \\ Campinas - SP \\ 28 de Junho à 02 de Julho de 2017
}

a 2009 , onde estes variaram de $15,4^{\circ} \mathrm{C}$ a $40,0^{\circ} \mathrm{C}$, estabelecendo-se assim uma amplitude termal de $24,6^{\circ} \mathrm{C}$. Observou-se que do total de dias analisados, 16 dias compreenderam 5\% dos dados, com temperaturas que variavam de $38,2^{\circ} \mathrm{C}$ a $40,0^{\circ} \mathrm{C}$, enquanto que os demais 3.552 dias, representaram $95 \%$ dos valores, obtendo temperaturas que variavam de $15,4^{\circ} \mathrm{C}$ a $38,1^{\circ} \mathrm{C}$.

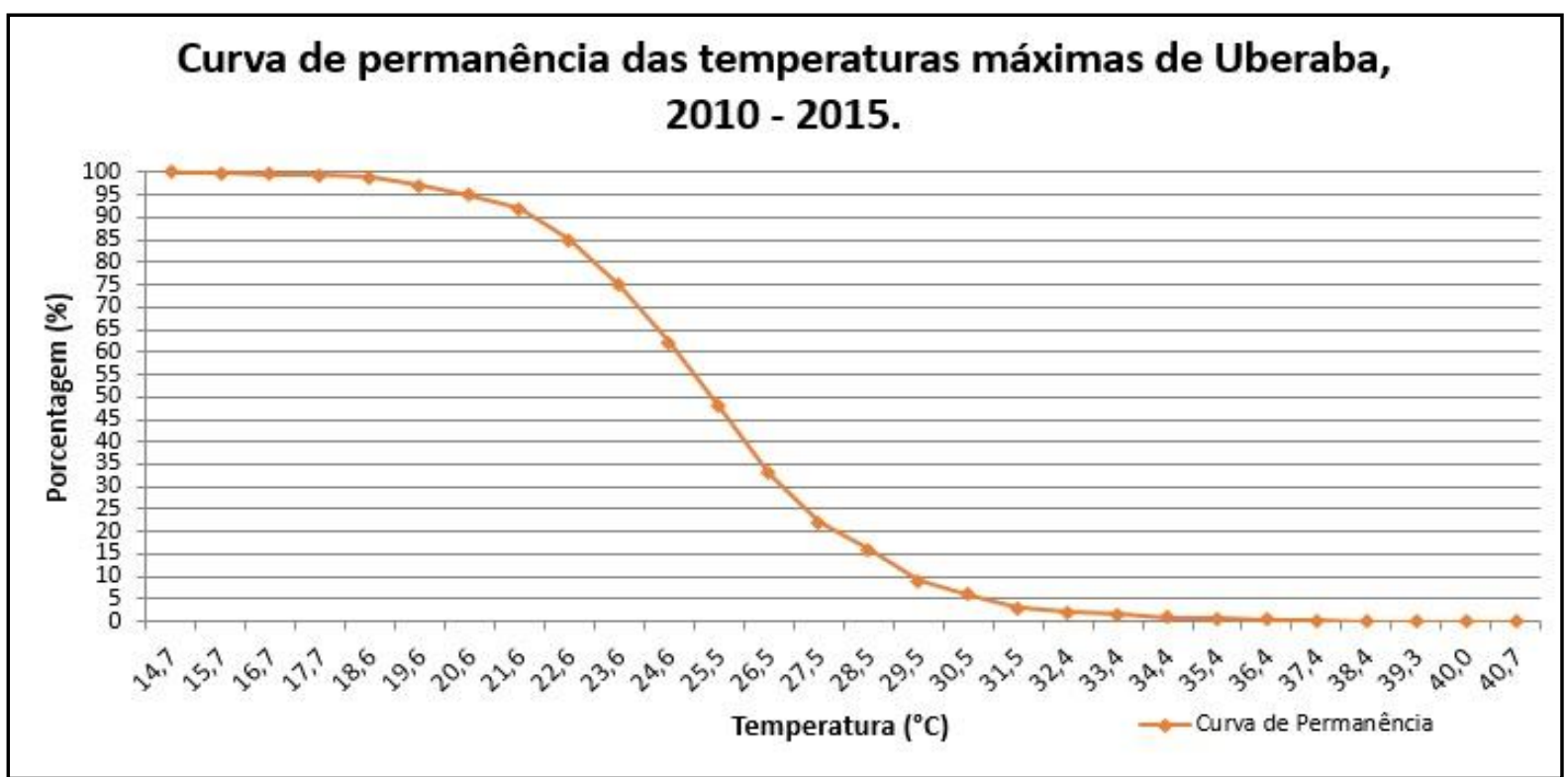

Figura 13 - Curva de permanência das temperaturas máximas de Uberaba, 2010 - 2015 Fonte dos dados: INMET (2016) - Acessado em março de 2016 Organização: SILVA (2016)

Os dados de temperatura máxima que foram utilizados para a confecção do histograma de curva de permanência (figura 13), representam um total de 2.191 dias de dados analisados, no período de 2010 a 2015 , onde estes variaram de $14,7^{\circ} \mathrm{C}$ a $40,7^{\circ} \mathrm{C}$, estabelecendo-se assim uma amplitude termal de $26,0^{\circ} \mathrm{C}$. Observou-se que do total de dias analisados, 14 dias compreenderam 5\% dos dados, com temperaturas que variavam de $39,3^{\circ} \mathrm{C}$ a $40,7^{\circ} \mathrm{C}$, enquanto que os demais 2.177 dias, representaram $95 \%$ dos valores, obtendo temperaturas que variavam de $14,7^{\circ} \mathrm{C}$ a $39,2^{\circ} \mathrm{C}$.

\title{
4 Conclusão
}

O método de padronização de dados faz-se de grande utilidade para estudos de clima, visto que este procedimento pode resultar na verificação de determinadas tendências e, a partir destas promover ações preventivas com o intuito de minimizar os danos decorrentes das mudanças climáticas.

Os resultados alcançados evidenciaram que o comportamento da curva de permanência seguiu uma tendência em todos os histogramas de temperatura média, onde os dados que correspondiam às maiores temperaturas representavam $5 \%$ do total de dados, enquanto que os demais dados representavam os outros 95\%. Os resultados obtidos através dos dados de temperatura máxima 
demonstraram a mesma tendência dos de temperatura média, onde suas temperaturas mais elevadas correspondiam a 5\% dos dados, e as demais temperaturas representavam os outros $95 \%$.

Como o objetivo do trabalho era encontrar e analisar possíveis anomalias de temperatura, ou seja, temperaturas que ocorreram poucas vezes ao longo da série histórica, verificamos que foi possível concluir este objetivo, uma vez que, as temperaturas médias e máximas mais elevadas, que representam a excepcionalidade, tiveram um nível de ocorrência muito baixa se comparadas com as demais temperaturas que formam a série histórica.

\section{Bibliografia}

AYOADE, J. O..Introdução a climatologia para os trópicos. 4. ed. Rio de Janeiro: Bertrand Brasil, 1996. 332 p.

BDMEP - Banco de Dados Meteorológicos para Ensino e Pesquisa. Disponível em: <http://www.inmet.gov.br/projetos/rede/pesquisa/inicio.php>. Acesso em: 15 de nov. de 2016.

CAMPOS, C. G. C.; BRAGA, H. J.; ALVES, R.. Mudanças climáticas atuais e seus impactos no estado de Santa Catarina. Agropecuária Catarinense, v. 19, p. 31-35, 2006.

IBGE - Instituto Brasileiro de Geografia e Estatística. Disponível em: <http://www.ibge.gov.br/>, acesso em 12 de nov. de 2015.

INMET - Instituto Nacional de Meteorologia. Disponível em: <http://www.inmet.gov.br/>, acesso em 03 de mar. de 2016.

OLIVEIRA, L. A.; SILVA, L. R. T.. Avaliação do índice de temperatura média e máxima no município de Lavras - MG. Revista Equador (online), v. 4, p. 1112-1119, 2015.

SANTOS, C. A. C. Estimativa e tendências de índices de detecção de mudanças climáticas com base na precipitação diária no Rio Grande do Norte e na Paraíba. Dissertação de Mestrado - Campina Grande, 2006.

TUCCI, C. E. M. (Org); da SILVEIRA, A. L. L; LANNA, A. E. L; BIDONE, F; SEMMELMANN, F; A. LOUZADA, J.A; BERTONI, J.C; FILHO, K.Z; BELTRAME, L. F. S; BORDAS, M. P; PESSOA, M. L; CAICEDO, N. L; CHEVALLIER, P; PORTO, R. L; CLARKE, R. T; Hidrologia: Ciência e Aplicação. $3^{a}$ Ed. Porto Alegre: Editora da UFGRS/ABRH, 2004. 943p. 